\title{
Salmon lice sampled from wild Atlantic salmon and sea trout throughout Norway display high frequencies of the genotype associated with pyrethroid resistance
}

\author{
Helene Børretzen Fjørtoft ${ }^{1,2, *}$, Frank Nilsen ${ }^{2}$, Francois Besnier ${ }^{3}$, Anne Stene ${ }^{1}$, \\ Pål Arne Bjørn ${ }^{3}$, Ann-Kristin Tveten ${ }^{1}$, Vidar Teis Aspehaug ${ }^{4}$, Bengt Finstad ${ }^{5}$, \\ Kevin Alan Glover ${ }^{2,3}$
}

\footnotetext{
${ }^{1}$ Department of Biological Sciences in Aalesund, Norwegian University of Science and Technology, 6025 Aalesund, Norway

${ }^{2}$ Sea Lice Research Center, Department of Biology, University of Bergen, 5020 Bergen, Norway

${ }^{3}$ Institute of Marine Research, 5817 Bergen, Norway

${ }^{4}$ PatoGen AS, 6025 Aalesund, Norway

${ }^{5}$ Norwegian Institute for Nature Research, 7485 Trondheim, Norway
}

\begin{abstract}
Atlantic salmon Salmo salar aquaculture is based on the use of open-pen sea cages, with the consequence that farmed fish are both recipients and sources of pathogens from surrounding waters. Currently, the parasitic salmon louse Lepeophtheirus salmonis represents the most critical biological challenge for salmonid aquaculture in the Atlantic Ocean. This has, in part, been driven by the emergence of resistance to the few delousing agents available to the industry. In the present study, we investigated resistance to pyrethroids. Lice sampled in 2014 from wild Atlantic salmon and sea trout Salmo trutta hosts from Norway were genotyped using the genetic marker associated with pyrethroid resistance and compared to data from lice sampled on farmed hosts in the same regions and period. The resistant genotype was observed in lice from both wild hosts in all regions of Norway. In all regions, frequencies of the resistant genotype were similar for lice from sea trout and farmed salmon, approaching fixation in some areas. In most regions, lice from wild salmon displayed lower frequencies of the resistant genotype than lice from both wild sea trout and farmed salmon. Lice are only directly exposed to chemical selection within aquaculture. Therefore, these data demonstrate an extensive gene flow and exchange of lice between farmed and wild salmonid hosts. It is also suggested that the observed lower frequency of the resistant genotype in lice from wild salmon returning to the coast is due to a dilution effect mediated by infestation with lice originating from outside farming areas while in the oceanic feeding grounds.
\end{abstract}

KEY WORDS: Lepeophtheirus salmonis $\cdot$ Resistance $\cdot$ Pyrethroid · Infestations · Aquaculture · Wild salmonids

\section{INTRODUCTION}

Atlantic salmon Salmo salar aquaculture has developed into a significant industry in several countries since its start in the early 1970 s. However, the rapid expansion of this industry has not been without sev-

${ }^{*}$ Corresponding author: helene.b.fjortoft@ntnu.no eral challenges linked with environmental sustainability (Taranger et al. 2015, Forseth et al. 2017). Of these challenges, farmed escapees causing genetic interactions with wild conspecifics (Glover et al. 2017) as well as infestations of salmon lice Lepeophtheirus salmonis on wild and farmed salmonids

() The authors 2019. Open Access under Creative Commons by Attribution Licence. Use, distribution and reproduction are unrestricted. Authors and original publication must be credited. 
(Torrissen et al. 2013, Thorstad \& Finstad 2018) represent two of the most significant challenges experienced in the North Atlantic.

Production-related challenges caused through infestation with the parasitic salmon louse are almost as old as modern salmonid aquaculture itself (Hastein \& Bergsjo 1976, Gjedrem 2007) and occur in farms in both the Pacific and Atlantic where the 2 sub-species of this parasite are endemic (Skern-Mauritzen et al. 2014). The life history characteristics of this parasite permit it to adapt quickly to new conditions. For example, at $10^{\circ} \mathrm{C}$, it only takes $\sim 40 \mathrm{~d}$ from egg hatching until male offspring are sexually mature and $45 \mathrm{~d}$ for females (Stien at al., 2005). Furthermore, fecundity is high in this species, and each pair of egg strings contains $\sim 500$ to 600 eggs at temperatures between 5 and $15^{\circ} \mathrm{C}$ (Samsing et al. 2016). In laboratory trials, females have been reported to produce up to 11 pairs of egg-strings (Heuch et al. 2000). Of further importance for the evolutionary success of this parasite is its ability to disperse. Population genetic and genomic studies have revealed a high level of genetic connectivity among lice sampled throughout the North Atlantic (Todd et al. 2004, Tjensvoll et al. 2006, Glover et al. 2011, Besnier et al. 2014). Despite the observed genetic homogeneity throughout the Atlantic, a spatial-temporal mosaic of allele frequencies is observed in the mutations causing resistance to delousing chemicals or in the genes in close proximity to the causative mutations (Besnier et al. 2014, Fjørtoft et al. 2017, Kaur et al. 2017, Jacobs et al. 2018). However, given the lack of any geographical population genetic structuring (Besnier et al. 2014), this probably reflects differences in the use of chemicals in time and space, rather than a temporally stable population genetic structure, as was also suggested by Jacobs et al. (2018).

The salmon louse's developmental stages immediately after hatching are planktonic and are thus spread by water currents. Simulations have predicted that larvae can drift up to $200 \mathrm{~km}$ before their energy reserves are spent (Asplin et al. 2011). However, the transport of lice over very large distances is through the migratory behavior of their wild hosts. Sea trout Salmo trutta and Arctic char Salvelinus alpinus, both hosts for the salmon louse, typically utilize coastal areas for feeding during the summer and may therefore contribute to dispersal of lice within and between fjord and coastal systems (Thorstad et al. 2016, Jensen et al. 2018). In addition, wild Atlantic salmon, also a major host of this parasite, undertake long-distance migrations to open oceanic areas where salmon from multiple countries and con- tinents meet (Bradbury et al. 2016, Olafsson et al. 2016, Gilbey et al. 2017). The presence of all stages of salmon lice on fish captured on the high seas, as well as upon return to the coastline, demonstrates that infestations with salmon lice may occur in the open ocean (Jacobsen \& Gaard 1997, Todd et al. 2000, 2006). As a result, returning wild Atlantic salmon may serve as a vector for salmon lice originating from different parts of the North Atlantic.

The salmonid aquaculture industry has tried to control the salmon louse using a variety of methods over the past 4 decades. These include the widespread use of chemotherapeutants (Brandal \& Egidius 1979, Jakobsen \& Holm 1990, Denholm et al. 2002), cleaner fish (Bjordal 1990), and, more recently, warm-water treatments (Grøntvedt et al. 2015) and the implementation of closed or semi-closed sea pens (Nilsen et al. 2017, Oppedal et al. 2017). However, the species' ability to adapt has reduced the efficiency of most chemotherapeutants in use (Aaen et al. 2015). For more than a decade, chemical treatment based on organophosphates was the dominating method to control salmon lice in European salmon farms (Denholm et al. 2002). When this treatment started to lose its effect due to the development of resistance, pyrethroids were gradually phased in. In Norwegian aquaculture, pyrethroids were first used commercially in 1994 (Denholm et al. 2002). However, treatment failures were reported already by 1998, and resistance was confirmed in 2000 (Sevatdal \& Horsberg 2000, 2003). In 1999, emamectin benzoate was introduced to Norwegian aquaculture for the first time as an 'in-feed' treatment and immediately became the preferred method for delousing (Denholm et al. 2002). However, within 11 yr after its introduction, resistance to this chemical was also documented (Espedal et al. 2013, Ljungfeldt et al. 2014), and a mutation(s) causing resistance had been dispersed throughout the North Atlantic after originating from a single source (Besnier et al. 2014).

Selection for mutations that cause reduced sensitivity or resistance to chemotherapeutants occurs at aquaculture sites that are repeatedly treated with the same compound over time (Denholm et al. 2002). Previously, it was postulated that as salmon lice found on wild salmonids are not directly exposed to chemicals, wild salmonids could serve as a refuge for chemical-sensitive lice (Murray 2011, McEwan et al. 2015). However, a recent study on the prevalence of the mutation Phe362Tyr, which is responsible for organophosphate resistance (Kaur et al. 2016, 2017), revealed that lice collected from wild sea trout displayed the same frequency of the resistant allele as 
lice sampled from farmed salmon in the same region (Fjørtoft et al. 2017). That study also reported high frequencies of the resistant allele on lice collected from wild Atlantic salmon returning to the Norwegian coast, albeit at a slightly lower frequency than on the sea trout and farmed salmon. It was then concluded that a major reason for the lower frequency of the mutation Phe362Tyr in lice collected from wild salmon was due to dilution (Fjørtoft et al. 2017). While in the open ocean, wild salmon was infected with lice originating from both farming and nonfarming areas, i.e. from areas both with and without selection for organophosphate resistance.

Reduced sensitivity to pyrethroids is associated with genetic variation in the mitochondrial genome (mtDNA) of the salmon louse (Nilsen \& Espedal 2015, Carmona-Antoñanzas et al. 2017, Bakke et al. 2018). In contrast to nuclear DNA, where one allele is inherited from the mother and one from the father, mtDNA is inherited solely from the mother. The exact mechanism of mitochondrial resistance remains elusive, and it is also suggested that more than one mutation, also nuclear, act together (Carmona-Antoñanzas et al. 2019). However, $C 14064 T$, a silent mutation in the mtDNA $c y t B$ gene that is non-causatively but tightly linked with pyrethroid resistance (due to the lack of recombination in mtDNA), has been identified and validated as a resistance marker for pyrethroids in $L$. salmonis (Nilsen \& Espedal 2015). From this, a high through-put assay has been developed to identify individual lice carrying the resistance marker (Nilsen \& Espedal 2015). The patented method (Nilsen \& Espedal 2015), which is based on a TaqMan assay to identify a sensitive and resistant genotype associated with resistance, has been used to screen for pyrethroid resistance in 15000 lice collected from fish farms throughout the entire North Atlantic in the period 2000 to 2017 (H. B. Fjørtoft et al. unpubl.). These data, together with the ability to genotype lice from wild salmonid hosts, provide a unique opportunity to address the following questions: (1) Do lice collected from wild salmonids display the same frequency of the resistant genotype as lice collected from farmed salmonids in the same region? (2) Are there differences in the frequency of the resistant genotype between lice collected on wild salmon and wild sea trout in the same region? To address these questions, we genotyped $~ 800$ lice from wild Atlantic salmon and sea trout hosts collected throughout Norway with the pyrethroid resistance marker and compared the frequency of the resistant genotype with that observed in lice collected on farmed salmonids from the same regions and time-frame.

\section{MATERIALS AND METHODS}

\subsection{Sampling salmon lice from wild sea trout and salmon}

A total of 826 salmon lice were collected from wild Atlantic salmon Salmo salar and sea trout Salmo trutta hosts along the entire Norwegian coastline in 2014 (Fig. 1). All necessary permits and permissions were obtained before samples were collected using gill nets, bag nets and at one location a fish trap (Fjørtoft et al. 2017). From each host, the fish weight, fish length and total number of lice were registered. In addition, a scale sample was taken from each host to determine sea age. Scales were also read to exclude escaped farmed salmon, based on differences in growth zones between wild and reared fish (Lund et al. 1991). Scale samples were not taken for the wild salmon collected in northern Norway (Finnmark).

For most regions studied, 50 salmon lice from each of the available wild host species were selected for genotyping (Table S1 in the Supplement at www.int-res.com/articles/suppl/q011p459_supp.pdf).

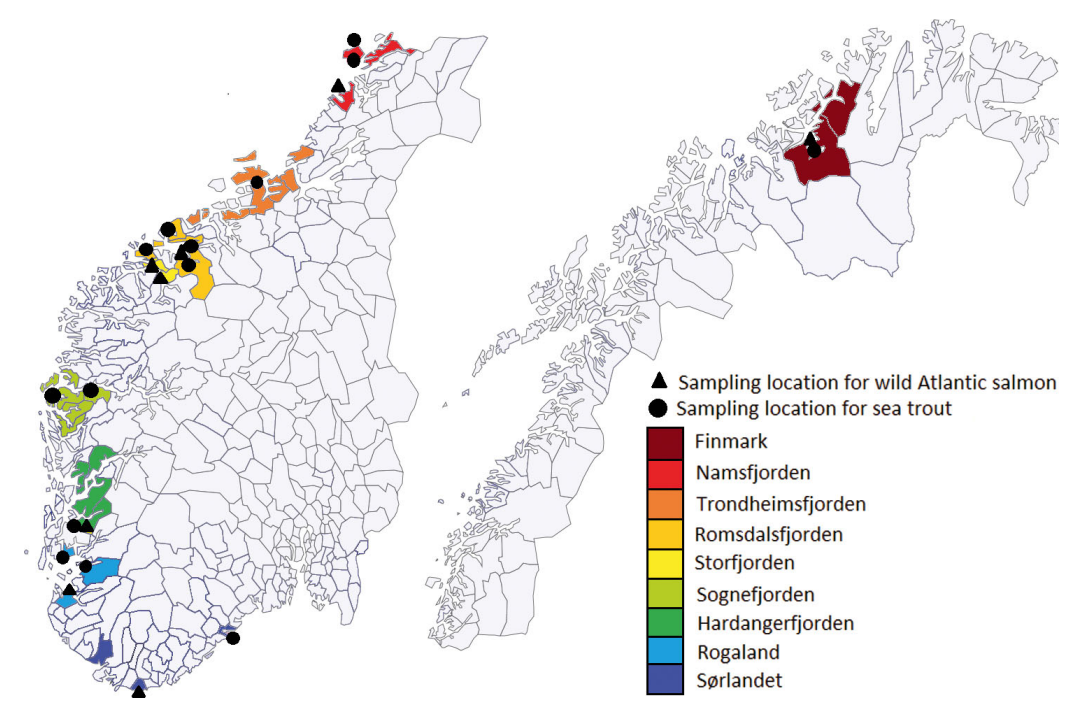

Fig. 1. Sampling locations for salmon lice from wild sea trout and wild Atlantic salmon. The corresponding regions based on data from fish farms are identified by colour. The background map is derived from Global Administrative Areas (2012) and R packages (Becker \& Wilks 1993, 1995, Pebesma \& Bivand 2005, Bivand et al. 2013) 
In cases where a host fish had $>10$ lice, the total number of lice collected for genetic analysis did not exceed 10. This was done to spread the lice collection among multiple hosts. In 3 of the regions, different numbers of lice were collected. In Romsdalsfjord, 200 salmon lice from sea trout were sampled, and from Rogaland and Sørlandet, only 45 and 12 salmon lice from wild Atlantic salmon were available.

\subsection{Genetic analysis of lice from wild hosts}

All samples of lice collected from wild hosts were genotyped for the recently developed genetic marker associated with pyrethroid resistance (Nilsen \& Espedal 2015). Genotyping was performed by PatoGen AS in their ISO certified laboratory according to their patented TaqMan assay for detection of this resistance marker (Nilsen \& Espedal 2015). In short, the assay used the following primers and probe: forward primer: 5'-TTC TTA CAG ACA AAG CTA AAG CCA CTA-3', reverse primer: 5'-AGT AAC TCC TGC TCA CAT TCA ACC T-3', probe: 5'-CCC CCC (C/T) AA CTT AT-3'. A 1-step amplification (45 cycles) was performed on their Applied Biosystems 7500 RealTime PCR System. Genotypes arising from the marker were thereafter categorized as resistant or susceptible because this is a mtDNA marker without heterozygotes as is the case for nuclear DNA markers. All raw data are available (Table S1).

\subsection{Data from aquaculture}

Data on the prevalence of the resistant genotype in $>10000$ lice sampled from fish in farms along the entire Norwegian coast are presented by $H$. B. Fjørtoft et al. (unpubl.). The same dataset was used in the present study in order to compare the prevalence of resistant lice sampled from wild and farmed hosts within regions. The genotype of the lice sampled from farmed salmon was obtained from the same method as for the lice from wild salmonids). To select the relevant sub-sets of data from the farms, a $50 \mathrm{~km}$ perimeter was set around the borders of the municipality where wild salmonids had been sampled. Thereafter, data on the frequency of the resistant genotype from all farms within this region were averaged to compare to the data from the lice collected on wild fish. The only exception to this rule was the region Sørlandet, where aquaculture activity is less intensive. Here, the distance between the wild sea trout sampling site and the closest farm that had been screened with the genetic marker is $\sim 190 \mathrm{~km}$. All lice from wild salmonids were sampled in 2014; thus, only results from fish farms in 2014 were used for comparison, except from Finnmark. Here, no data from 2014 were available, but as a proxy, 30 salmon lice from 1 location in 2013 and 89 salmon lice from 3 locations in 2015 were used for comparison (Table S1). Genotyping results from a total of 2304 lice sampled from farmed salmon throughout the Norwegian coast were included in this study (Table S1).

All delousing treatments are reported to the Norwegian food safety authorities and are publicly available (BarentsWatch 2017). The standing biomass of salmonids in Norwegian aquaculture is reported at county level for each month (Directorate of Fisheries 2018). The average yearly biomass was used to estimate the treatment intensity at county level (Fig. 2). As a measure of pyrethroid treatment intensity, the number of pyrethroid treatments in a county and year was divided by the average biomass in thousand tons. This proxy was used to compare between years and counties and to test the relationship between treatment intensity and the prevalence of resistant salmon lice on the available host species within each county.

\subsection{Statistics}

All statistical analyses were performed in the software and programming language $\mathrm{R}$ (R Core Team 2017). The frequency of the resistant genotype was modeled as a binary response to host type, sea-age,

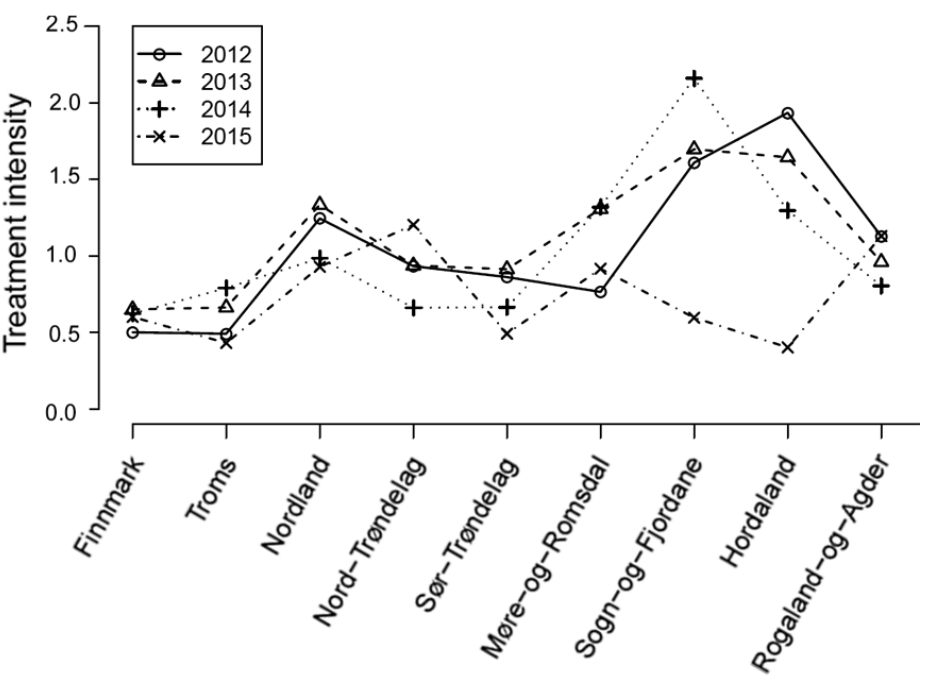

Fig. 2. Pyrethroid treatment intensity on Norwegian fish farms in the period 2012 to 2015 . Treatment intensity is given by number of treatments per thousand tons of standing biomass at county level. Data collected from BarentsWatch (2017) and Directorate of Fisheries (2018) 
treatment intensity and sampling regions in a GLM framework. The significance of each covariate was obtained from chi-squared tests implemented in the glm.anova function in R. Differences in frequencies of the resistant genotype between lice from the 2 host species within each region were tested using a chisquared test. As each region was tested separately, 21 tests were performed, giving a Bonferroni corrected threshold for significance of 0.002 , corrected from 0.05 .

For the wild Atlantic salmon with known sea age, the frequencies of the resistant genotype in the sampled salmon lice were compared between the cohorts, both at the regional level and for the total sample. Differences in frequencies between regions were also tested for each host type separately. Correlations between host species and the treatment index of each region was tested both for the year 2014 and for the accumulated treatment index for the years 2012 to 2014.

For all statistical tests, a significance level of 0.05 was used. The maps in the figures were made using the 'maps' package in $\mathrm{R}$ along with freely available data from Global Administrative Areas (2012) (https: //cran.r-project.org/web/packages/maps/maps.pdf)
(Becker \& Wilks 1993, 1995, Pebesma \& Bivand 2005, Bivand et al. 2013).

\section{RESULTS}

The genotype associated with pyrethroid resistance was detected in salmon lice collected from wild salmonids along the entire Norwegian coast (Fig. 3, Table S1). The highest frequency in lice from wild salmonids (95.8\%) was found in a sample taken from sea trout Salmo trutta in the Sognefjord, while the lowest frequency $(10 \%)$ was found in a sample from sea trout captured at Sørlandet. The frequency of the resistant genotype in salmon lice sampled from wild Atlantic salmon Salmo salar ranged from 14.9\% (Namsfjord) to $44 \%$ (Hardangerfjord). In salmon lice sampled from farmed salmon, the frequency ranged from $15.1 \%$ at Sørlandet to $96.2 \%$ in the Hardangerfjord.

There was no significant difference in the frequency of the resistant genotype between salmon lice collected from sea trout and farmed salmon in any of the regions (Fig. 4, p-values in Table S2). In contrast, the frequency of the resistant genotype in

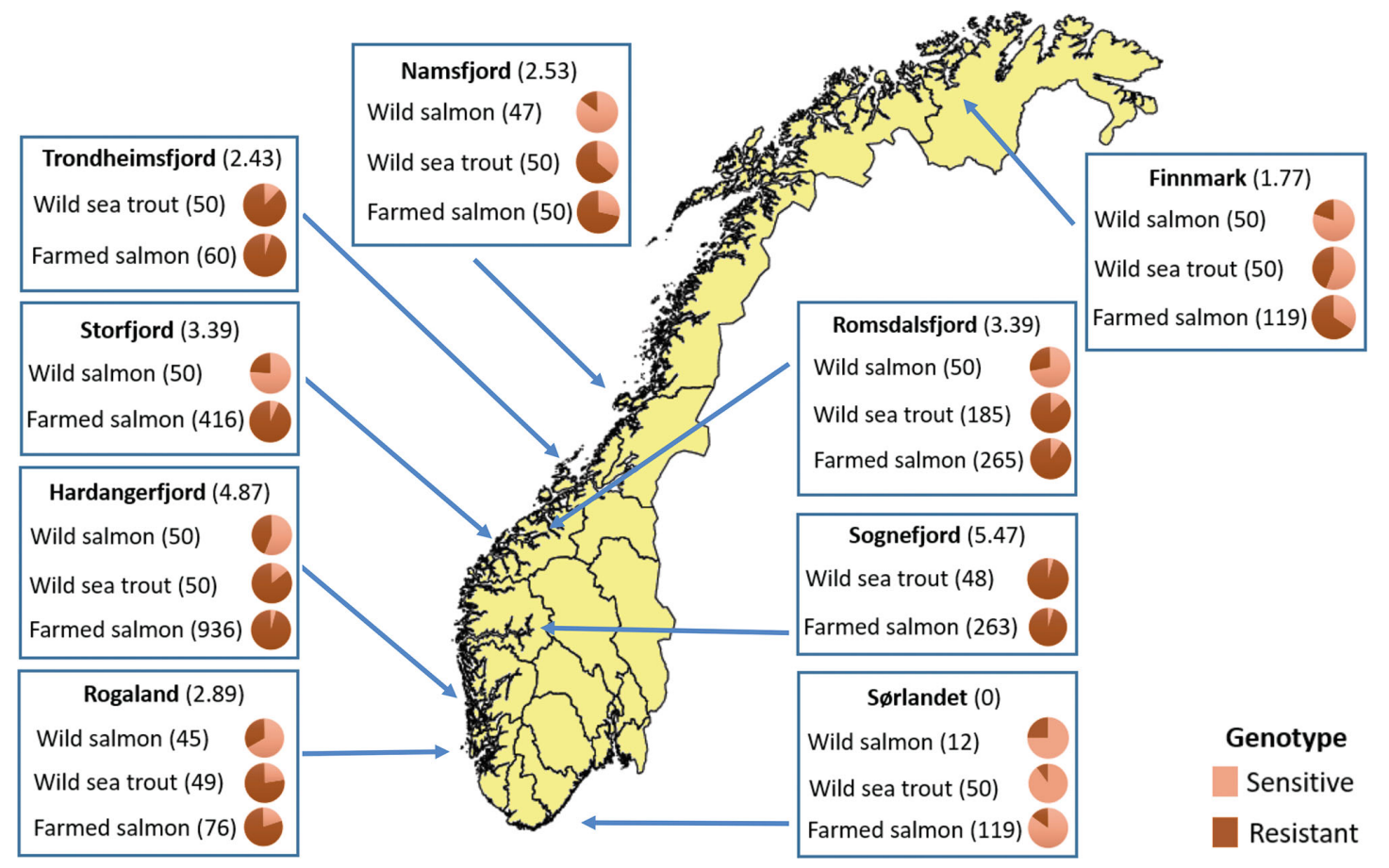

Fig. 3. Genotype (resistant or sensitive) frequency of the pyrethroid resistance marker in salmon lice sampled from wild Atlantic salmon, wild sea trout and farmed salmon along the Norwegian coast in 2014. These data are based on analysis of 826 lice from wild and 2304 lice from farmed salmonids. The number of salmon lice tested from each host within each region is given in parenthesis. The accumulated treatment index for the years 2012 to 2014 is given in parenthesis after the name of each region. The background map is derived from Global Administrative Areas (2012) and R packages (Becker \& Wilks 1993, 1995, Pebesma \& Bivand 2005, Bivand et al. 2013) 


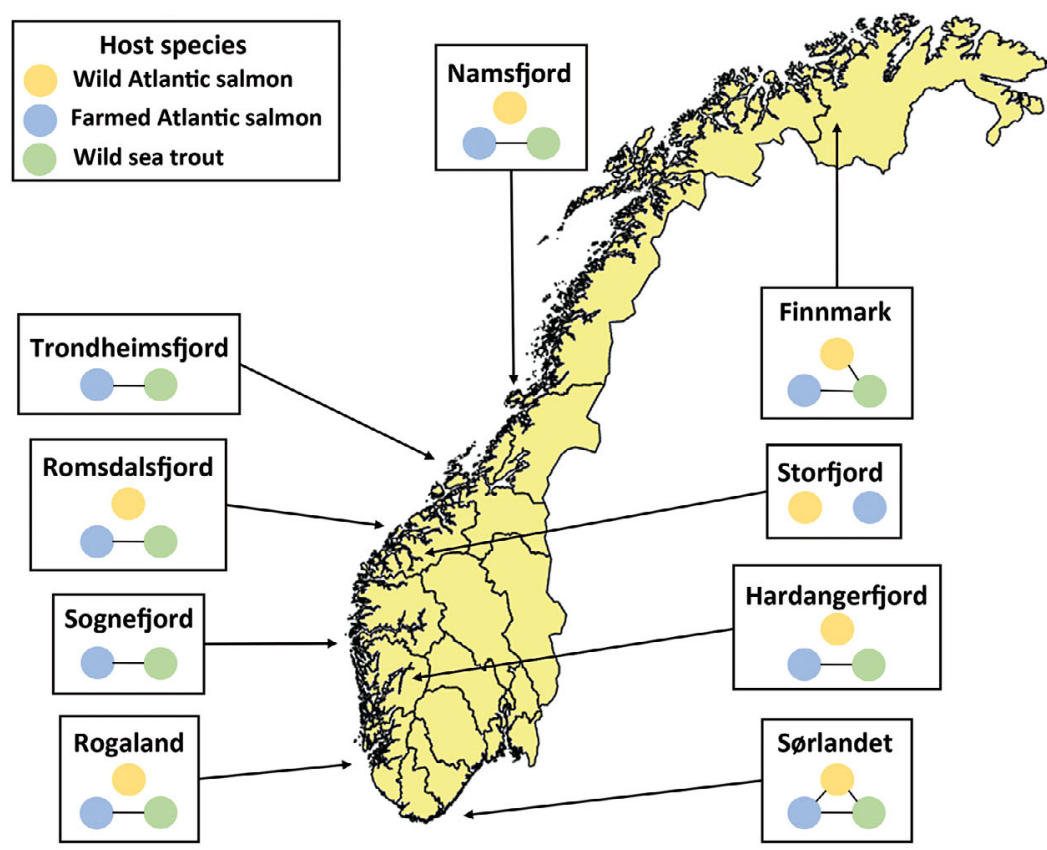

Fig. 4. Frequencies of the pyrethroid resistant genotype compared between host types. In each region, the frequencies of the resistance marker from each host group are compared to the other available host groups. Where there is no significant difference between 2 host groups, they are connected with a line. If there are significant differences, there is no line between the 2 groups. The background map is derived from Global Administrative Areas (2012) and R packages (Becker \& Wilks 1993, 1995, Pebesma \& Bivand 2005, Bivand et al. 2013)

lice collected from wild Atlantic salmon was significantly lower than in salmon lice from farmed salmon in all regions except Sørlandet (Fig. 4, Table S2). In the regions Finnmark and Sørlandet, there was no significant difference in frequencies of the resistant genotype between salmon lice collected from wild Atlantic salmon and sea trout, but in the other regions that were tested (Rogaland, Hardangerfjord, Romsdalsfjord and Namsfjord), resistant genotype frequency was higher in lice from wild sea trout than from wild salmon (Fig. 4, Table S2).

Across all of the salmon lice sampled on wild Atlantic salmon, no significant correlation between the sea age of the salmon host from which the lice were collected and frequency of the resistant genotype in the lice was observed $(p=0.17)$. The same was found when testing within each geographic region separately ( $p$-values in Table S3), with the exception of Romsdalsfjord ( $p=0.009)$. In this region, there was a higher frequency of the sensitive genotype in lice collected from fish of older sea age; however, the number of samples for both 1 sea winter old fish and 3 sea winter old fish was low (6 and 9, respectively) and therefore needs to be treated with caution.
The frequency of the resistant genotype in lice collected from sea trout was strongly correlated with geographic region $(\mathrm{p}<0.0001)$. The correlation between region and frequency of the resistant genotype in salmon lice from wild Atlantic salmon was also significant $(p=0.04)$, albeit much weaker than for the relationship observed in sea trout. When the treatment index of the different regions was considered, the trend was similar: there was a strong correlation between the frequency of the resistant genotype in salmon lice from sea trout and the treatment index for 2014 ( $p<0.0001)$, while the correlation was marginally insignificant for the frequency of the resistant genotype in salmon lice from wild Atlantic salmon $(p=0.06)$. When the accumulated treatment index for 2012 to 2014 was used, the result was the same for lice from sea trout $(p<0.0001)$, while the correlation between frequency of resistance in salmon lice from wild Atlantic salmon and accumulated treatment index was weaker but significant $(\mathrm{p}=0.008)$.

\section{DISCUSSION}

This is the first study to investigate the distribution and prevalence of pyrethroid resistance in salmon lice sampled from wild Atlantic salmon Salmo salar and sea trout Salmo trutta hosts. The most significant results are: (1) The genotype associated with pyrethroid resistance was found in lice collected from wild salmon and sea trout in all regions of Norway; (2) The frequency of the resistant genotype was very similar in lice collected from wild sea trout and farmed salmon within the same regions, and in some regions this approached fixation; (3) The frequency of the resistant genotype was higher in lice collected from farmed salmon than in lice from wild salmon returning from their oceanic migration to regions of intensive aquaculture.

All of the main findings of this study are in strong accordance with the results of a similar study investigating the distribution and prevalence of the organophosphate-resistant mutation Phe362Tyr (Kaur et al. 2016, 2017) in wild salmon and sea trout in Norway (Fjørtoft et al. 2017). Therefore, based on the 
results of the present study, and that of the earlier study on organophosphate resistance, we conclude that there is extensive gene flow and exchange of lice between farmed and wild salmonid hosts in aquaculture-dense regions of Norway. We further conclude that wild salmon returning to Norway from their oceanic migration display a slightly lower frequency of the resistance to chemotherapeutants in part due to infection with lice from salmon originating from outside farming areas where there is no selection for resistance.

Results from the present study and Fjørtoft et al. (2017) showed the same tendencies using 2 different genetic markers that are associated with 2 different delousing chemicals and mechanisms of resistance, i.e. that wild sea trout and farmed salmon share the same pool of lice in aquaculture-intense regions of Norway. The frequency of the genotype associated with pyrethroid resistance varied in time and space, and was dependent on the local use of the relevant chemotherapeutants, as demonstrated in the present study by comparing the frequencies of the resistant genotype with treatment intensity. In areas where pyrethroids have been used extensively over time, there is a very high frequency of the resistant genotype, both in lice collected from sea trout and farmed salmon. Because salmon lice residing on wild sea trout are not directly exposed to pyrethroids, the high frequency of the resistant genotype found in lice from sea trout can only be explained by a high level of cross-infestation of lice from aquaculture. This does not mean that all resistant lice sampled from sea trout in the present study were hatched in a fish farm, but over time, the repeated use of pyrethroids in an area has almost eradicated lice carrying the sensitive genotype. As a result, primarily resistant lice have been able to reproduce and disperse to both farmed and wild salmonids.

Wild Atlantic salmon typically spend 1 to 3 yr on the oceanic feeding grounds where salmon originating from different countries and continents may meet (Bradbury et al. 2016, Gilbey et al. 2017). Upon return to their rivers of origin, wild salmon may bring back salmon lice that have settled during the oceanic stage (Jacobsen \& Gaard 1997, Todd et al. 2000, 2006). The origin of these lice might be both regions of intensive aquaculture and regions hosting only wild salmonids. Lice originating from areas outside aquacultureintense regions have not been under direct selection for resistance to delousing chemicals. The observed lower frequency of the genotype associated with pyrethroid resistance on wild salmon returning to the coastline could also be due to higher mortality or lower fecundity of lice carrying this marker, i.e. a fitness cost. However, if this was the primary driver of that observation, one may have expected a lower frequency of the resistant genotype also in lice collected from wild sea trout. This was not observed. In addition, the observed lack of correlation between the sea age of the salmon host and the frequency of the resistant genotype excludes the possibility that the frequency in lice collected on wild salmon reflects the situation of resistance in that area in the year that the fish went to sea (i.e. 1 to $3 \mathrm{yr}$ earlier). The fact that the frequencies found on the returning salmon were lower than what was observed in most Norwegian fish farms back to 2012 supports this result (H. B. Fjørtoft et al. unpubl.). Thus, we believe that the primary reason for the lower frequency of pyrethroid (and organophosphate) resistant lice on wild salmon returning to the Norwegian coastline is due to crossinfestation and dilution at the high seas with lice from salmon that originate from outside aquacultureintense regions and thus display a lower frequency of resistance. This suggested mechanism of connectivity is in accordance with studies that have demonstrated little population-genetic structuring in salmon lice throughout the Atlantic (Todd et al. 2004, Tjensvoll et al. 2006, Glover et al. 2011, Besnier et al. 2014), with the exception of temporary pockets of divergence linked with time-space variations in extent and type of chemical delousing usage (Besnier et al. 2014, Jacobs et al. 2018).

As was the case for the study conducted on wild salmonids (Fjørtoft et al. 2017) on the frequency of the mutation Phe362Tyr that conveys resistance to organophosphates (Kaur et al. 2016), we conclude that sea trout cannot be regarded as a refuge of pyrethroid-sensitive lice. Returning wild salmon, on the other hand, may have a delaying effect when pyrethroids are used actively and a diluting effect when the usage has stopped (due to the crossinfection mechanisms in the open ocean as described above). However, the magnitude of contribution from wild salmon is modest in Norway, as farmed salmon outnumber returning adult wild salmon $\sim 100$-fold (Forseth et al. 2017). Thus, even with the strict regulations that are currently in place, only allowing 0.5 adult female lice per fish in each fish pen, the high number of farmed salmon still results in a much higher production of salmon lice compared to the contribution from wild salmonids (Heuch \& Mo 2001).

Wild hosts of salmon lice are numerous in the fjords in the spring, summer and autumn when wild salmon migrate between the native river and the oceanic feeding grounds, and sea trout and Arctic char 
Salvelinus alpinus feed in the fjords (Jensen et al. 2018). During winter months, fjords are empty of wild Atlantic salmon and Arctic char. Some sea trout remain in the fjords after their first summer in sea and have been recorded in the sea during the winter months in both southern and northern areas (see Thorstad et al. 2016 and references therein). In aquaculture-dense regions, however, large numbers of farmed salmon are continuously accessible for lice in open net-pens throughout the year. Wild fish migrating out of the rivers in the spring have no lice attached. Therefore, the primary source of salmon lice copepodids in the spring is local fish farms, with some contribution from wild Atlantic salmon returning to the coastline and some sea trout remaining in sea during the winter period. For sea trout in aquaculture regions, it is highly likely that especially the first salmon lice infestations in the spring originate from lice having overwintered on farmed salmon in the surrounding region. In turn, these salmon lice will follow the host in the fjords and coastal areas and produce offspring that can infest both wild and farmed salmonids.

A practical consideration from the results of the present study investigating pyrethroid resistance and those based upon organophosphate resistance (Fjørtoft et al. 2017) is that the aquaculture industry cannot rely upon lice infestations from wild salmonids to reduce the frequency of resistance in lice on farmed fish. As long as there are wild sea trout or Arctic char in coastal regions or fjords, it is unlikely that fallowing an entire region will greatly reduce the frequency of resistance in lice in that area, as wild salmonids will infest the new farmed salmon with lice carrying the same frequencies of resistance as before. By fallowing during winter, when the fjords have reduced numbers of wild salmonids, the returning wild salmon in the early summer may be a significant source of salmon lice recruits. This could theoretically lead to a slight reduction in the levels of resistance in lice on both farmed and wild salmonids in the fjords. However, introduction of salmon lice from neighboring regions through water currents or migrating salmonids and new treatments with the relevant chemotherapeutants could result again in the rapid development of higher frequencies of resistance .

Acknowledgements. This study was financed by resources from the Norwegian Ministry of Trade, Fisheries and Industry (NFD), the Norwegian Food Safety Authority (Mattilsynet) and Regional Research Fond (RRF) grant no: 245912. The authors extend their gratitude to all of those assisting in sampling lice from wild salmonids, especially people working at the Institute of Marine Research and local fishermen.

\section{LITERATURE CITED}

Aaen SM, Helgesen KO, Bakke MJ, Kaur K, Horsberg TE (2015) Drug resistance in sea lice: a threat to salmonid aquaculture. Trends Parasitol 31:72-81

Asplin L, Boxaspen KK, Sandvik AD (2011) Modeling the distribution and abundance of planktonic larval stages of Lepeophtheirus salmonis in Norway. In: Jones $\mathrm{S}$, Beamish R (eds) Salmon lice: an integrated approach to understanding parasite abundance and distribution. Wiley-Blackwell, Oxford, p 29-50

* Bakke MJ, Agusti C, Bruusgaard JC, Sundaram AYM, Horsberg TE (2018) Deltamethrin resistance in the salmon louse, Lepeophtheirus salmonis (Krøyer): maternal inheritance and reduced apoptosis. Sci Rep 8:8450

* BarentsWatch (2017) Norwegian fish health. www.barentswatch.no/en/fishhealth/ (accessed February 2018)

* Becker RA, Wilks AR (1993) Maps in S. AT\&T Bell Laboratories Statistics Research Report [93.2]. http://ect.belllabs.com/sl/doc/93.2.ps

Becker RA, Wilks AR (1995) Constructing a geographical database. AT\&T Bell Laboratories Statistics Research Report [95.2]. http://ect.bell-labs.com/sl/doc/95.2.ps

Besnier F, Kent M, Skern-Mauritzen R, Lien S and others (2014) Human-induced evolution caught in action: SNParray reveals rapid amphi-Atlantic spread of pesticide resistance in the salmon ectoparasite Lepeophtheirus salmonis. BMC Genomics 15:937

Bivand RS, Pebesma E, Gomez-Rubio V (2013). Applied spatial data analysis with R, 2nd Edn. Springer, New York, NY

Bjordal Å (1990) Sea lice infestation on farmed salmon: possible use of cleaner-fish as an alternative method for delousing. Can Tech Rep Fish Aquat Sci 1761:85-89

* Bradbury IR, Hamilton LC, Sheehan TF, Chaput G and others (2016) Genetic mixed-stock analysis disentangles spatial and temporal variation in composition of the West Greenland Atlantic Salmon fishery. ICES J Mar Sci 73: 2311-2321

* Brandal PO, Egidius E (1979) Treatment of salmon lice (Lepeophtheirus salmonis Kroyer, 1838) with Neguvondescription of method and equipment. Aquaculture 18: 183-188

Carmona-Antoñanzas G, Bekaert M, Humble JL, Boyd S and others (2017) Maternal inheritance of deltamethrin resistance in the salmon louse Lepeophtheirus salmonis (Krøyer) is associated with unique mtDNA haplotypes. PLOS ONE 12:e0180625

Carmona-Antoñanzas G, Helgesen KO, Humble JL, Tschesche C and others (2019) Mutations in voltagegated sodium channels from pyrethroid resistant salmon lice (Lepeophtheirus salmonis). Pest Manag Sci 75: 527-536

Denholm I, Devine GJ, Horsberg TE, Sevatdal S, Fallang A, Nolan DV, Powell R (2002) Analysis and management of resistance to chemotherapeutants in salmon lice Lepeophtheirus salmonis (Krøyer) (Copepoda: Caligidae). Pest Manag Sci 58:528-536

Directorate of Fisheries (2018) Statistics for aquaculture. www.fiskeridir.no/English/Aquaculture/Statistics/Atlant ic-salmon-and-rainbow-trout (accessed February 2018)

Espedal PG, Glover KA, Horsberg TE, Nilsen F (2013) Emamectin benzoate resistance and fitness in laboratory reared salmon lice (Lepeophtheirus salmonis). Aquaculture 416-417:111-118 
Fjørtoft HB, Besnier F, Stene A, Nilsen F and others (2017) The Phe362Tyr mutation conveying resistance to organophosphates occurs in high frequencies in salmon lice collected from wild salmon and trout. Sci Rep 7: 14258

Forseth T, Barlaup BT, Finstad B, Fiske P and others (2017) The major threats to Atlantic salmon in Norway. ICES J Mar Sci 74:1496-1513

* Gilbey J, Wennevik V, Bradbury IR, Fiske P, Hansen LP, Jacobsen JA, Potter T (2017) Genetic stock identification of Atlantic salmon caught in the Faroese fishery. Fish Res 187:110-119

Gjedrem T (2007) Akvaforsk i nasjonal og internasjonal akvakultur. Akvaforsk, Ås

Global Administrative Areas (2012) GADM database of Global Administrative Areas, version 2.0. www.gadm.org

* Glover KA, Stølen ÅB, Messmer A, Koop BF, Torrissen O, Nilsen F (2011) Population genetic structure of the parasitic copepod Lepeophtheirus salmonis throughout the Atlantic. Mar Ecol Prog Ser 427:161-172

Glover KA, Solberg MF, McGinnity P, Hindar K and others (2017) Half a century of genetic interaction between farmed and wild Atlantic salmon: status of knowledge and unanswered questions. Fish Fish 18:890-927

Grøntvedt RN, Nerbøvik IKG, Viljugrein H, Lillehaug A, Nilsen H, Gjevre AG (2015) Thermal de-licing of salmonid fish - documentation of fish welfare and effect. Report Series 13. Norwegian Veterinary Institute, Oslo

Hastein T, Bergsjo T (1976) The salmon lice Lepeophtheirus salmonis as the cause of disease in farmed salmonids. Riv Ital Piscic Ittiopatol 11:3-5

Heuch PA, Mo TA (2001) A model of salmon louse production in Norway: effects of increasing salmon production and public management measures. Dis Aquat Org 45: 145-152

Heuch PA, Nordhagen JR, Schram TA (2000) Egg production in the salmon louse [Lepeophtheirus salmonis (Kroyer)] in relation to origin and water temperature. Aquacult Res 31:805-814

Jacobs A, De Noia M, Praebel M, Kanstad-Hanssen $\varnothing$ and others (2018) Genetic fingerprinting of salmon louse populations in the North-East Atlantic using a random forest classification approach. Sci Rep 8:1203

Jacobsen JA, Gaard E (1997) Open-ocean infestation by salmon lice (Lepeophtheirus salmonis): comparison of wild and escaped farmed Atlantic salmon (Salmo salar L.). ICES J Mar Sci 54:1113-1119

Jakobsen P, Holm JC (1990) Promising tests with a new compound against sea lice. Norsk Fiskeoppdrett 1:16-18 (in Norwegian)

Jensen AJ, Finstad B, Fiske P (2018) Evidence for the linkage of survival of anadromous Arctic char and brown trout during winter to marine growth during the previous summer. Can J Fish Aquat Sci 75:663-672

* Kaur K, Jansen PA, Aspehaug VT, Horsberg TE (2016) Phe362Tyr in AChE: a major factor responsible for azamethiphos resistance in Lepeophtheirus salmonis in Norway. PLOS ONE 11:e0149264

Kaur K, Besnier F, Glover KA, Nilsen F, Aspehaug VT, Fjørtoft HB, Horsberg TE (2017) The mechanism (Phe362Tyr mutation) behind resistance in Lepeophtheirus salmonis pre-dates organophosphate use in salmon farming. Sci Rep 7:12349

Ljungfeldt LER, Espedal PG, Nilsen F, Skern-Mauritzen M, Glover KA (2014) A common-garden experiment to quantify evolutionary processes in copepods: the case of emamectin benzoate resistance in the parasitic sea louse Lepeophtheirus salmonis. BMC Evol Biol 14:108

* Lund RA, Okland F, Hansen LP (1991) Farmed Atlantic salmon (Salmo salar) in fisheries and rivers in Norway. Aquaculture 98:143-150

* McEwan GF, Groner ML, Fast MD, Gettinby G, Revie CW (2015) Using agent-based modelling to predict the role of wild refugia in the evolution of resistance of sea lice to chemotherapeutants. PLOS ONE 10:e0139128

Murray AG (2011) A simple model to assess selection for treatment-resistant sea lice. Ecol Modell 222:1854-1862

Nilsen F, Espedal PG (2015) Method for detection of pyrethroid resistance in crustaceans and oligonucleotide sequences useful in detection of pyrethroid resistance. F Nilsen, PG Espedal, inventors; Bergen Teknologioverforing AS, Patogen AS, owners. Canadian Patent Application CA 2920588 A1. 2015 Feb 12

Nilsen A, Nielsen KV, Biering E, Bergheim A (2017) Effective protection against sea lice during the production of Atlantic salmon in floating enclosures. Aquaculture 466: $41-50$

* Olafsson K, Einarsson SM, Gilbey J, Pampoulie C, Hreggvidsson GO, Hjorleifsdottir S, Gudjonsson S (2016) Origin of Atlantic salmon (Salmo salar) at sea in Icelandic waters. ICES J Mar Sci 73:1525-1532

* Oppedal F, Samsing F, Dempster T, Wright DW, Bui S, Stien LH (2017) Sea lice infestation levels decrease with deeper 'snorkel' barriers in Atlantic salmon sea-cages. Pest Manag Sci 73:1935-1943

Pebesma EJ, Bivand RS (2005) Classes and methods for spatial data in R. R News 5. https://cran.r-project.org/doc/ Rnews/

R Core Team (2017) R: a language and environment for statistical computing. R Foundation for Statistical Computing, Vienna

Samsing F, Oppedal F, Dalvin S, Johnsen I, Vågseth $\mathrm{T}$, Dempster T (2016) Salmon lice (Lepeophtheirus salmonis) development times, body size, and reproductive outputs follow universal models of temperature dependence. Can J Fish Aquat Sci 73:1841-1851

Sevatdal S, Horsberg TE (2000) Kartlegging av pyretroidresistens hos lakselus. Nor Fiskeoppdrett 12:34-35

Sevatdal S, Horsberg TE (2003) Determination of reduced sensitivity in sea lice (Lepeophtheirus salmonis Krøyer) against the pyrethroid deltamethrin using bioassays and probit modelling. Aquaculture 218:21-31

* Skern-Mauritzen R, Torrissen O, Glover KA (2014) Pacific and Atlantic Lepeoptheirus salmonis (Krøyer, 1838) are allopatric subspecies: Lepeoptheirus salmonis salmonis and Lepeoptheirus s. oncorhynchi subspecies novo. BMC Genet 15:32

* Stien A, Bjørn PA, Heuch PA, Elston DA (2005) Population dynamics of salmon lice Lepeophtheirus salmonis on Atlantic salmon and sea trout. Mar Ecol Prog Ser 290: 263-275

* Taranger GL, Karlsen O, Bannister RJ, Glover KA and others (2015) Risk assessment of the environmental impact of Norwegian Atlantic salmon farming. ICES J Mar Sci 72: 997-1021

Thorstad EB, Finstad B (2018) Impacts of salmon lice emanating from salmon farms on wild Atlantic salmon and sea trout. NINA Report 1449, Norwegian Institute for Nature Research, Trondheim

Thorstad EB, Todd CD, Bjørn PA, Gargan PG and others 
(2016) Marine life of the sea trout. Mar Biol 163:47

Tjensvoll K, Glover KA, Nylund A (2006) Sequence variation in four mitochondrial genes of the salmon louse Lepeophtheirus salmonis. Dis Aquat Org 68:251-259

Todd CD, Walker AM, Hoyle JE, Northcott SJ, Walker AF, Ritchie MG (2000) Infestation of wild adult Atlantic salmon (Salmo salar L.) by the ectoparasitic copepod sea louse Lepeophtheirus salmonis Krøyer: prevalence, intensity and the spatial distribution of males and females on the host fish. Hydrobiologia 429:181-196

Todd CD, Walker AM, Ritchie MG, Graves JA, Walker AF (2004) Population genetic differentiation of sea lice (Lep-

Editorial responsibility: Ian Fleming,

St. John's, Newfoundland and Labrador, Canada eophtheirus salmonis) parasitic on Atlantic and Pacific salmonids: analyses of microsatellite DNA variation among wild and farmed hosts. Can J Fish Aquat Sci 61: $1176-1190$

Todd CD, Whyte BDM, MacLean JC, Walker AM (2006) Ectoparasitic sea lice (Lepeophtheirus salmonis and Caligus elongatus) infestations of wild, adult, one sea-winter Atlantic salmon Salmo salar returning to Scotland. Mar Ecol Prog Ser 328:183-193

* Torrissen O, Jones S, Asche F, Guttormsen A and others (2013) Salmon lice - impact on wild salmonids and salmon aquaculture. J Fish Dis 36:171-194

Submitted: January 21, 2019; Accepted: July 3, 2019

Proofs received from author(s): August 30, 2019 